\title{
SELETIVIDADE E EFICÁCIA DAS FORMULAÇÕES COM OS HERBICIDAS ATRAZINE/ DIMETHENAMID-P E ATRAZINE/DIMETHENAMID, NO CONTROLE DE PLANTAS DANINHAS NA CULTURA DO MILHO
}

\author{
JULIO P. LACA-BUENDÍA ${ }^{1}$ \\ (1) Eng. Agr., M.Sc., Pesq./EPAMIG/CTTP/FEGV Caixa Postal, 351 Uberaba, MG CEP 38060- \\ 040 .E-mail: juliolaca@epamiguberaba.com.br
}

\section{RESUMO}

O objetivo do ensaio foi estudar a seletividade e o controle de plantas daninhas anuais das misturas formuladas de dimethenamid-p $204 \mathrm{~g} / \mathrm{L} /$ atrazine $396 \mathrm{~g} / \mathrm{L}$ e dimethenamid $280 \mathrm{~g} / \mathrm{L} /$ atrazine $320 \mathrm{~g} / \mathrm{L}$, em pré-emergência, na cultura do milho (cv. Primaiz BR 3101 híbrido triplo). O solo foi um Latossolo Vermelho-Amarelo, textura média, em Uberaba, MG. Os tratamentos testados foram: dimethenamid-p $204 \mathrm{~g} / \mathrm{L} /$ atrazine $396 \mathrm{~g} / \mathrm{L}$, nas doses de 1800, 2100, $2400 \mathrm{e}$ $2700 \mathrm{~g} / \mathrm{há}$ do i. a.; dimethenamid $280 \mathrm{~g} / \mathrm{L} /$ atrazine $320 \mathrm{~g} / \mathrm{L}$, nas doses de 2100, 2400, $2700 \mathrm{e}$ $3000 \mathrm{~g} / \mathrm{há}$ do i. a.; s-metolachlor $960 \mathrm{~g} / \mathrm{L}$, na dose de $2880 \mathrm{~g} / \mathrm{há}$ do i. a. e testemunha capinada e testemunha sem capina. As misturas formuladas de dimethenamid-p/atrazine e dimethenamid/atrazine, independentemente das doses utilizadas proporcionaram eficiente controle de Bidens pilosa (picão-preto), Portulaca oleracea (beldroega), Commelina benghalensis (trapoeraba) e Digitaria horizontalis (capim-colchão). Não foram observadas diferenças significativas entre as produtividades nos diversos tratamentos químicos, mas 0 rendimento foi menor na testemunha sem capina $75 \%$ em relação a testemunha capinada. A aplicação dos tratamentos não afetou significativamente a população final, altura da planta, altura de inserção da primeira espiga e o peso de 100 sementes. No índice de colheita mecânica nos tratamentos químicos verificou-se que os maiores valores foram alcançados com as misturas formuladas de dimethenamid-p/ atrazine, na dose de $2700 \mathrm{~g} / \mathrm{ha}$ do i. a., com 4,5 e dimethenamid/atrazine, na dose de $2700 \mathrm{~g} / \mathrm{ha}$, com 3,8, sendo que nas outras doses testadas das misturas de dimethenamid-p/atrazine e dimethenamid/atrazine, apresentaram índice de colheita entre 3,2 a 3,8 . Todos os tratamentos químicos testados foram seletivos para o milho cv.Primaiz.

Palavras-chave: controle químico, Bidens pilosa, Portulaca oleracea, Commelina benghalensis, Digitaria horizontalis

\section{EFICACY AND SELECTIVITY OF FORMULATED MIXTURES OF ATRAZINE/ DIMETHENAMID-P AND ATRAZINE/DIMETHAMID IN THE WEED CONTROL IN CORN}

\begin{abstract}
A trial was carried out to test the efficacy and selective of formulation and doses of atrazine/ dimethenamid-p andatrazine/dimethenamid, in pre-emergence on corn (cv. Primaiz BR 3101). The following treatments were tested in a sandy Red Yellow Latossol soil, in Uberaba, Brazil: atrazine $396 \mathrm{~g} / \mathrm{L} /$ dimethenamid-p $204 \mathrm{~g} / \mathrm{L}$ (1800, 2100, 2400 and $2700 \mathrm{~g} / \mathrm{ha}$ ) and atrazine $320 \mathrm{~g} / \mathrm{L} /$ dimethenamid $289 \mathrm{~g} / \mathrm{L}(2100,2400,2700$ and $3000 \mathrm{~g} / \mathrm{ha}), \mathrm{s}$-metolachlor $960 \mathrm{~g} / \mathrm{L}$ (2880 $\mathrm{g} / \mathrm{ha}$ ) and hand weeding and weeded. The mixture of atrazine/dimethenamid- $\mathrm{p}$ and atrazine/ dimethenamid, independently of the rates provided good control of the weeds Bidens pilosa, Portulaca oleracea, Commelina benghalensis and Digitaria horizontalis. No significant differences was observed in the productivities of the chemical treatments, but weeded treatment reduced $72 \%$ of the crop yield in relation to the hand weeding treatment. These was no difference among treatments concerning to the crops density, cobs numbers and first cob height and seed weight. The harvest index for mechanical harvesting in the chemical treatments was excellent. All the tested treatments were selective to corn.
\end{abstract}

Word-key: Weed control, Bidens pilosa, Portulaca oleracea, Commelina benghalensis, Digitaria horizontalis 


\section{INTRODUÇÃO}

No Brasil, durante o ano agrícola de 1998/99, o milho apresentou uma produção de grãos de 25 milhões de toneladas em uma área de 8,5 milhões de ha, com rendimento médio de $2.942 \mathrm{~kg} / \mathrm{ha}$ (Levantamento Sistemático de Produção, 1999).

As gramíneas (200 perfilhos $/ \mathrm{m}^{2}$ ), provocam prejuízos por competição na produção do milho, na ordem de $47 \%$. Os efeitos da competição são neutralizados quando o controle das plantas daninhas se faz no período-controle que vai da emergência do milho aos 45 dias do seu ciclo (Blanco et al., 1976).

Segundo Ramos \& Pitelli (1993), o período anterior à competição (PAI) e período total de prevenção de interferência (PTPI) foram respectivamente, de 10 dias e 42 dias para o de menor incidência e de 14 dias e 42 dias para o de maior incidência e crescimento da comunidade infestante. Em estudo realizado para quatro híbridos de milho, o controle aos 15 dias após a emergência reduziu a matéria seca das plantas daninhas em mais de $90 \%$ e foi suficiente para alcançar o máximo de produtividade de grãos (Souza, 1996).

Silva (1999), verificou que quando a capina é iniciada nos estádios iniciais (até a abertura da sexta folha), as perdas na produção de grãos em relação à pós-emergência precoce (duas folhas) não foram significativas, atingindo em média 2,94\%. A partir da sexta folha, com a lígula já visível, a interferência das plantas daninhas foi mais acentuada do que nos estádios anteriores. As perdas percentuais atingiram, na média de três locais, 7,40\% para o estádio de seis folhas e 9,59\% para o estádio de sete folhas. As perdas percentuais verificadas quando a capina foi realizada somente até o pendoamento não foram diferentes significativamente das observadas quando a capina se estendeu até o fim do ciclo. O controle de plantas daninhas na cultura do milho não deve ser realizado o mais cedo possível, não ultrapassando o estádio da abertura da sexta folha do milho e devendo estender-se pelo menos até o pendoamento.

Indicações de herbicidas na cultura do milho para o controle das plantas daninhas, tem sido estudada por vários pesquisadores, conforme pode ser observado pelos trabalhos desenvolvidos por Oliveira et al., 1991; Velini et al., 1993; Dario et al.,1993; Laca-Buendia \& Leites, 1993; Rezende et al., 1993; Mascarenhas \& Lara, 1993; Laca-Buendia \& Ferreira, 1993; Laca-Buendia \& Ferreira, 1995; Marcondes et al., 1997. Barros et al., 1997; Carvalho et al., 1997 e Laca-Buendia \& Ferreira, 1997.

O objetivo do presente ensaio de campo foi avaliar a eficácia e seletividade das misturas formuladas dos herbicidas dimethenamid-p 204g/L/atrazine 396g/L e dimethenamid $280 \mathrm{~g} / \mathrm{L} /$ atrazine $320 \mathrm{~g} / \mathrm{L}$, aplicados em pré-emergência, em área total para o controle de plantas daninhas na cultura do milho, em áreas de Cerrado.

\section{MATERIAL E MÉTODOS}

O ensaio de campo foi instalado na Fazenda da Escola Agrotecnica Federal de Uberaba, no município de Uberaba, MG, no ano agrícola de 1998/99, em solo de Cerrado do tipo Latossolo-Vermelho-Amarelo, textura média, com $80 \%$ de areia, $13 \%$ de argila, $7 \%$ de silte, contendo $1,2 \%$ de matéria orgânica e pH (água) $=6,0$.

A cultivar de milho usada foi Primaiz BR 3101 híbrido triplo, plantada em 05/12/98, utilizando-se o espaçamento de 0,90 m entre fileiras, com sementes tratadas com Captan $75 \%$ na doses de $1,0 \mathrm{~kg} / \mathrm{kg}$ de semente e Pirimophos-metil a $50 \%$ na dose de $0,008 \mathrm{ml} / \mathrm{kg}$ de semente, com semeadura de tração mecânica, densidade de 5 sementes por metro linear.

A adubação de semeadura usada foi de $370 \mathrm{~kg} / \mathrm{ha}$ da fórmula $4: 30: 16$ de NPK $+6 \%$ de cálcio e $3,0 \%$ de enxofre. Na adubação nitrogenada de cobertura foram usadas duas aplicações, sendo a primeira com $250 \mathrm{~kg} / \mathrm{ha}$ da fórmula 10:10:10 de NPK aos 30 dias após emergência e a segunda após 24 dias da primeira, utilizando-se $250 \mathrm{~kg} / \mathrm{ha}$ de sulfato de amônia.

O ensaio foi instalado no delineamento experimental de blocos casualizados, com quatro repetições em parcelas de 5,0m x 3,2m, proporcionando uma área total de $16,0 \mathrm{~m}^{2}$, sendo colhidas as duas fileiras centrais, proporcionando uma área útil de $9,0 \mathrm{~m}^{2}$.

Os herbicidas foram aplicados em pré-emergência, em 06/12/98, utilizando-se um pulverizador costal pressurizado a $\mathrm{CO}_{2}$, dotado de barra, com quatro pontas do tipo leque 110.03 a $0,5 \mathrm{~m}$ de altura do solo, com consumo de calda de $237 \mathrm{~L} / \mathrm{ha}$, pressão constante de 60 $\mathrm{lb} / \mathrm{pol}^{2}$, entre $9 \mathrm{~h}$ e $45 \mathrm{~min}$ a $10 \mathrm{~h}$ e $30 \mathrm{~min}$. O céu encontrava-se nublado, sem vento e o solo 
úmido, após uma chuva de $27,7 \mathrm{~mm}$, com temperatura do ar de $22,4^{\circ} \mathrm{C}$ e umidade relativa de $88 \%$.

Para o controle das plantas daninhas na testemunha capinada, foram realizadas três capinas manuais para o controle das plantas daninhas, em 19/12/98; 10/01/99 e 30/01/99.

Foram realizadas avaliações visuais de fitotoxicidade das plantas de milho aos 7 e 15 dias após a aplicação das misturas formuladas, através da escala visual EWRC de 1 a 9 , onde 1 = sem injúria e $9=$ morte da planta.

Tabela 1- Tratamentos, formulações, nomes comerciais e doses dos produtos utilizados em pós-emergência.Uberaba, MG, 1999.

\begin{tabular}{|c|c|c|c|}
\hline \multirow[t]{2}{*}{ Herbicidas } & \multicolumn{2}{|c|}{ Doses } & \multirow{2}{*}{$\begin{array}{c}\text { Nome } \\
\text { comercial }\end{array}$} \\
\hline & i. a. $(g / h a)$ & p. c. (L/ha) & \\
\hline atrazine 396g/L/dimethenamid-p 204g/L (") & 1800 & 3,0 & BAS 625 UDH \\
\hline atrazine 396g/L/dimethenamid-p 204g/L $\mathrm{L}^{(*)}$ & 2100 & 3,5 & BAS $625 \mathrm{UDH}$ \\
\hline atrazine 396g/L/dimethenamid 204g/L (") & 2400 & 4,0 & BAS 625 UDH \\
\hline atrazine 396g/L/dimethenamid-p 204g/L (") & 2700 & 4,5 & BAS 625 UDH \\
\hline atrazine $320 \mathrm{~g} / \mathrm{L} /$ dimethenamid $280 \mathrm{~g} / \mathrm{L}^{\left({ }^{*}\right)}$ & 2100 & 3,5 & Guarsdman \\
\hline atrazine $320 \mathrm{~g} / \mathrm{L} /$ dimethenamid $280 \mathrm{~g} / \mathrm{L}^{\left({ }^{(*)}\right.}$ & 2400 & 4,0 & Guarsdman \\
\hline atrazine $320 \mathrm{~g} / \mathrm{L} /$ dimethenamid $280 \mathrm{~g} / \mathrm{L}^{\left({ }^{*}\right)}$ & 2700 & 4,5 & Guarsdman \\
\hline atrazine $320 \mathrm{~g} / \mathrm{L} /$ dimethenamid $280 \mathrm{~g} / \mathrm{L}^{\left({ }^{*}\right)}$ & 3000 & 5,0 & Guarsdman \\
\hline s-metolachlor $960 \mathrm{~g} / \mathrm{L}$ & 2880 & 3,0 & DualGold \\
\hline Testemunha capinada & --- & --- & --- \\
\hline Testemunha sem capina & --- & --- & --- \\
\hline
\end{tabular}

$\left({ }^{\star}\right)$ Mistura formulada

Tabela 2- Precipitações pluviais, em mm, ocorridas durante a condução do ensaio de campo. Uberaba, MG 1998/99.

\begin{tabular}{l|c|c|c|c}
\hline \multicolumn{1}{c|}{ Mês } & 1 $^{\underline{0}}$ Decêndio & $2^{\underline{0}}$ Decêndio & $3^{\underline{0}}$ Decêndio & Total \\
\hline Dezembro & 92,4 & 116,4 & 92,5 & 301,3 \\
\hline Janeiro & 187,2 & 62,8 & 175,2 & 425,2 \\
\hline Fevereiro & 23,1 & 58,1 & 79,4 & 161,1 \\
\hline Março & 61,2 & 50,7 & 73,1 & 185,0 \\
\hline Abril & 4,0 & 14,5 & 0,0 & 18,5 \\
\hline Maio & 23,3 & 0,0 & 0,0 & 23,3 \\
\hline Total & \multicolumn{4}{r|}{} \\
\hline
\end{tabular}

Aos 21, 51, e 67 dias após a aplicação foram feitas avaliações da eficácia de controle das plantas daninhas presentes, utilizando-se a escala percentual de $0 \%$ a $100 \%$, onde $0 \%=$ nenhum controle e $100 \%$ controle total. $\mathrm{Na}$ área útil de cada parcela e na testemunha sem capina foi realizada a contagem de todos os indivíduos por espécie de plantas daninhas de maior abundância dentro da área útil de cada parcela numa área de $1 \mathrm{~m}^{2}$.

Antes da colheita foi realizada uma avaliação visual para colheita mecânica segundo a escala visual: 1-impossível ( $100 \%$ a $79 \%$ de infestação); 2 -alta infestação ( $80 \%$ a $59 \%$ de infestação); 3- infestação razoável (60\% a 39\% de infestação); 4- boa colheita ( $40 \%$ a $19 \%$ de infestão) e 5-excelente (ótimo) ( $20 \%$ a $0 \%$ de infestação).

Quando as plantas de milho atingiram a maturação dos grãos foi realizada a colheita (12/04/99), onde se realizou a pesagem dos grãos da área útil e contou-se o número de indivíduos $/ 9,0 \mathrm{~m}^{2}$ de cada parcela. A altura média das plantas e a altura de inserção da primeira espiga, foram avaliadas em 10 plantas, ao acaso, dentro de duas fileiras centrais de cada parcela. Contou-se o número de espigas/parcela dentro da área útil. Foram escolhidas, ao acaso 100 sementes para determinar seu peso em cada parcela.

\section{RESULTADOS E DISCUSSÃO}

As espécies daninhas encontradas foram: Bidens pilosa (picão- preto), com 50,0 indivíduos $/ \mathrm{m}^{2}$, Portulaca oleracea (beldroega), com 36,0 indivíduos $/ \mathrm{m}^{2}$, Commelina 
benghalensis (trapoeraba), com 30,0 indivíduos $/ \mathrm{m}^{2}$ e Digitaria horizontalis (capim-colchão), com 25,0 perfilhos $/ \mathrm{m}^{2}$.

De acordo com os resultados, verificamos que, para a densidade final, altura da planta, inserção da primeira espiga, número de espigas por parcela e do peso de 100 sementes, não foram detectadas diferenças estatísticas entre as misturas dos herbicidas nas doses testadas com a testemunha capinada (Tabela 3 ).

Nenhuma das misturas prontas testadas, apresentaram efeitos de fitotoxicidade nas plantas de milho, observando-se nota EWRC 1 (sem injúria), observando-se que estas misturas nas doses testadas apresentam alta seletividade para a cultura (Tabela 3).

No rendimento de grãos, foram encontradas diferenças significativas, sendo que todos os tratamentos com as misturas de herbicidas testadas não apresentaram diferenças com a testemunha capinada. A competição das plantas daninhas apresentou uma diminuição na produtividade de grão de $75 \%$ em relação a testemunha capinada (Tabela 3 ).

$\mathrm{Na}$ avaliação de colheita mecânica, houve diferenças significativas entre tratamentos, verificando-se que os maiores valores foram obtidos com as misturas dos herbicidas dimethenamid-p/atrazine na dose de $2700 \mathrm{~g} / \mathrm{ha}$, com 4,5 e dimethenamid/atrazine na dose de $2700 \mathrm{~g} / \mathrm{ha}$, com 3,8, sendo que as outras doses testadas das misturas formuladas de dimethenamid-p/atrazine e dithenamid/atrazine, apresentaram nota entre 3,2 a 3,8 (Tabela 3).

Tabela 4- Resultados médios da percentagem de Bidens pilosa obtidas na avaliação de eficácia das formulações dos herbicidas atrazine/dimethenamid- $p$ e atrazine/ dimethanamid no controle de plantas daninhas na cultura do milho. Uberaba, MG. 1998/99.

\begin{tabular}{|c|c|c|c|c|}
\hline \multirow[t]{2}{*}{ Tratamentos } & \multirow{2}{*}{$\begin{array}{l}\text { Doses } \\
\text { i. a. (g/ha) }\end{array}$} & \multicolumn{3}{|c|}{ Bidens pilosa $^{(1)}$} \\
\hline & & $21 \mathrm{DAA}$ & 51 DAA & 67 DAA \\
\hline atrazine/dimethenamid-p & 1800 & $95,8 b^{(2)}$ & $94,2 \mathrm{~b}$ & $92,0 \mathrm{~b}$ \\
\hline atrazine/dimethenamid-p & 2100 & $97,2 \mathrm{~b}$ & $96,5 b$ & $95,0 \mathrm{~b}$ \\
\hline atrazine/dimethenamid- $p$ & 2400 & $97,2 b$ & $96,5 b$ & $95,0 \mathrm{~b}$ \\
\hline atrazine/dimethenamid-p & 2700 & $98,5 b$ & $98,0 \mathrm{~b}$ & $97,2 b$ \\
\hline atrazine/dimethenamid & 2100 & $97,2 b$ & $96,5 b$ & $95,2 b$ \\
\hline atrazine/dimethenamid & 2400 & $97,5 b$ & $96,5 b$ & $95,7 b$ \\
\hline atrazine/dimethenamid & 2700 & $98,0 a b$ & $96,5 b$ & $96,5 b$ \\
\hline atrazine/dimethenamid & 3000 & $98,2 a b$ & $97,2 b$ & $96,5 b$ \\
\hline s-metolachlor & 2880 & $87,5 c$ & $85,0 \mathrm{c}$ & $82,5 c$ \\
\hline Testemunha capinada & --- & $100,0 a$ & $100,0 \mathrm{a}$ & $100,0 a$ \\
\hline Testemunha sem capina & --- & $0,0 \mathrm{~d}$ & $0,0 \mathrm{~d}$ & $0,0 \mathrm{~d}$ \\
\hline Número de indivíduos $/ \mathrm{m}^{2}$ & & 55,0 & 32,5 & 43,0 \\
\hline Valor de F & & $263,8^{* *}$ & $410,5^{\star \star}$ & $293,7^{* \star}$ \\
\hline C. V.(\%) & & 4,2 & 3,4 & 4,0 \\
\hline
\end{tabular}

Para o controle do picão-preto, foi verificado um controle eficiente por todas as doses testadas das misturas formuladas dos herbicidas dimethenamid-p/atrazine e dimethenamid/ atrazine, sendo que o s-metolachlor foi o herbicida que apresentou o menor controle $(82,5 \%)$, e as outras misturas formuladas de herbicidas apresentaram índices entre 92\% a 97,2\% (Tabela 4). Para a beldroega, todas as doses testadas das misturas formuladas e s-metolachlor nas doses testadas, apresentaram índice entre 95\% a 97,2\% (Tabela 5). A trapoeraba, foi controlada por todos as misturas formuladas de herbicidas e s-metolachlor nas doses testadas, com índices entre $93 \%$ a $96,5 \%$ (Tabela 6). Para o capim-colchão, todas as misturas formuladas dos herbicidas e s-metolachlor nas doses testadas, apresentaram índices entre $91,8 \%$ a 96,5\%, até 67 dias após a aplicação (Tabela 7).

De forma geral, a atrazine 396g/L/dimethenamid-p 204g/L, nas doses de 1800, 2100, 2400 e $2700 \mathrm{~g} / \mathrm{ha}$ do i. a. apresentou um eficiente controle para picão-preto (Bidens pilosa), beldroega (Portulaca oleracea), trapoeraba (Commelina bengalhensis) e capim-colchão (Digitaria horizontalis). A atrazine $320 \mathrm{~g} / \mathrm{L} /$ dimethenamid $280 \mathrm{~g} / \mathrm{L}$, nas doses de 2100, 2400, 2700 e 3000g/ha do i. a., mostrou eficácia no controle para picão-preto (Bidens pilosa), beldroega (Portulaca oleracea), trapoeraba (Commelina bengalhensis) e capim-colchão (Digitaria horizontalis). O s-metolachlor a $2880 \mathrm{~g} / \mathrm{ha}$ do i. a. mostrou eficácia no controle para 
beldroega (Portulaca oleracea), trapoeraba (Commelina bengalhensis) e capim-colchão (Digitaria horizontalis). As misturas formuladas de atrazine 396g/L/dimethenamid-p $204 \mathrm{~g} / \mathrm{L}$ e atrazine $320 \mathrm{~g} / \mathrm{L} /$ dimethenamid $280 \mathrm{~g} / \mathrm{L}$ e s-metolachlor $960 \mathrm{~g} / \mathrm{L}$, nas doses testadas, apresentaram seletividade para a cultura do milho.

Tabela 5- Resultados médios da percentagem de controle de Commelina benghalensis obtidas na avaliação de eficácia das formulações dos herbicidas atrazine/ dimethenamid-p e atrazine/dimethanamid no controle de plantas daninhas na cultura do milho. Uberaba, MG. 1998/99.

\begin{tabular}{|c|c|c|c|c|}
\hline \multirow[t]{2}{*}{ Tratamentos } & \multirow{2}{*}{$\begin{array}{r}\text { Doses } \\
\text { i. a. }(\mathrm{g} / \mathrm{ha})\end{array}$} & \multicolumn{3}{|c|}{ Commelina benghalensis ${ }^{(1)}$} \\
\hline & & $21 \mathrm{DAA}$ & $51 \mathrm{DAA}$ & 67 DAA \\
\hline atrazine/dimethenamid-p & 1800 & $96,5 b^{(2)}$ & $95,7 b$ & $94,2 b$ \\
\hline atrazine/dimethenamid-p & 2100 & $96,7 b$ & $95,7 b$ & $94,5 b$ \\
\hline atrazine/dimethenamid-p & 2400 & $97,5 b$ & $97,2 b$ & $95,5 b$ \\
\hline atrazine/dimethenamid-p & 2700 & $98,0 b$ & $97,2 b$ & $95,7 b$ \\
\hline atrazine/dimethenamid & 2100 & $98,0 \mathrm{~b}$ & $97,2 b$ & $94,5 b$ \\
\hline atrazine/dimethenamid & 2400 & $96,5 b$ & $95,7 b$ & $95,7 b$ \\
\hline atrazine/dimethenamid & 2700 & $95,0 \mathrm{~b}$ & $94,2 b$ & $93,0 \mathrm{~b}$ \\
\hline atrazine/dimethenamid & 3000 & $97,7 b$ & $97,5 b$ & $96,5 b$ \\
\hline s-metolachlor & 2880 & $97,7 \mathrm{~b}$ & $97,7 b$ & $95,7 b$ \\
\hline Testemunha capinada & --- & $100,0 a$ & $100,0 a$ & $100,0 a$ \\
\hline Testemunha sem capina & --- & $0,0 c$ & $0,0 c$ & $0,0 \mathrm{c}$ \\
\hline Número de indivíduos $/ \mathrm{m}^{2}$ & & 30,5 & 23,0 & 14,0 \\
\hline Valor de F & & $417,3^{\star \star}$ & $409,2^{* \star}$ & $431,2^{\star \star}$ \\
\hline C. V.(\%) & & 3,3 & 3,3 & 3,2 \\
\hline
\end{tabular}

Tabela 6- Resultados médios de percentagem de controle de Portulaca oleracea em das obtidas na avaliação de eficácia das formulações com os herbicidas atrazine/ dimethenamid-p e atrazine/dimethanamid no controle de plantas daninhas na cultura do milho. Uberaba, MG. 1998/99.

\begin{tabular}{l|c|ccc}
\hline \multicolumn{1}{c}{ Tratamentos } & Doses & \multicolumn{3}{|c}{ Portulaca oleracea $^{(1)}$} \\
\cline { 3 - 5 } & i. a. $(\mathrm{g} / \mathrm{ha})$ & $21 \mathrm{DAA}$ & $51 \mathrm{DAA}$ & $67 \mathrm{DAA}$ \\
\hline atrazine/dimethenamid-p & 1800 & $93,0 \mathrm{~b}^{(2)}$ & $93,5 \mathrm{~b}$ & $96,5 \mathrm{~b}$ \\
atrazine/dimethenamid-p & 2100 & $93,5 \mathrm{~b}$ & $94,2 \mathrm{~b}$ & $96,5 \mathrm{~b}$ \\
atrazine/dimethenamid-p & 2400 & $97,2 \mathrm{~b}$ & $96,5 \mathrm{~b}$ & $97,2 \mathrm{~b}$ \\
atrazine/dimethenamid-p & 2700 & $97,2 \mathrm{~b}$ & $96,5 \mathrm{~b}$ & $97,2 \mathrm{~b}$
\end{tabular}




\begin{tabular}{lcrrr} 
atrazine/dimethenamid & 2100 & $93,5 \mathrm{~b}$ & $95,0 \mathrm{~b}$ & $96,5 \mathrm{~b}$ \\
atrazine/dimethenamid & 2400 & $96,5 \mathrm{~b}$ & $96,5 \mathrm{~b}$ & $97,2 \mathrm{~b}$ \\
atrazine/dimethenamid & 2700 & $96,7 \mathrm{~b}$ & $96,7 \mathrm{~b}$ & $97,2 \mathrm{~b}$ \\
atrazine/dimethenamid & 3000 & $96.5 \mathrm{~b}$ & $96,5 \mathrm{~b}$ & $97,2 \mathrm{~b}$ \\
S-metolachlor & 2880 & $95,0 \mathrm{~b}$ & $93,0 \mathrm{~b}$ & $95,0 \mathrm{~b}$ \\
Testemunha capinada & --- & $100,0 \mathrm{a}$ & $100,0 \mathrm{a}$ & $100,0 \mathrm{a}$ \\
Testemunha sem capina & -- & $0,0 \mathrm{c}$ & $0,0 \mathrm{c}$ & $0,0 \mathrm{c}$ \\
Número de_indivíduos/m ${ }^{2}$ & 41,0 & 14,5 & 11,0 \\
\hline Valor de F & $382,4^{\star *}$ & $338,1^{* *}$ & $348,6^{* *}$ \\
C. V.(\%) & 3,4 & 3,7 & 3,6 \\
\hline${ }^{(1)}$ Dados transformados em Arc. Seno & $\sqrt{x / 100}$ para efetuar a análise da variância. & DAA=dias após a \\
aplicação. \\
(2) As médias na mesma coluna seguidas pela mesma letra, não diferem estatisticamente entre si, pelo teste de Tukey \\
ao nível de 5\% de probabilidade.
\end{tabular}

Tabela 7- Resultados médios de percentagem controle de Digitaria horizontalis obtidas na avaliação de eficácia das formulações com os herbicidas atrazine/dimethenamid-p e atrazine/dimethanamid no controle de plantas daninhas na cultura do milho. Uberaba, MG. 1998/99.

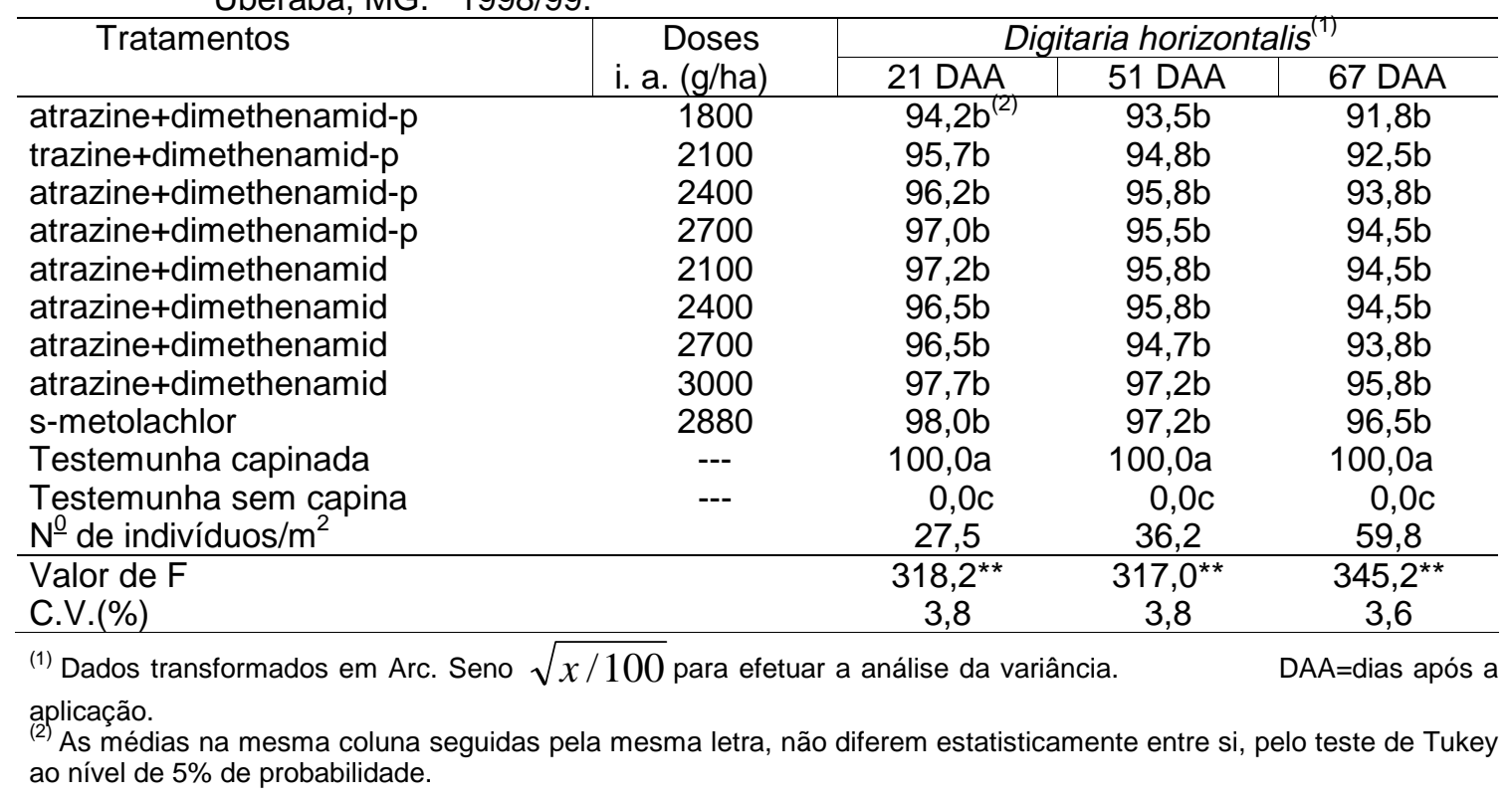

\section{BIBLIOGRAFIA CONSULTADA}

BARROS, A. C. de; QUEIROZ, P. R. M. de; MOURA, E. Controle pré-emergente de plantas daninhas na cultura do milho com a mistura atrazine+isoxaflutolre e atrazine+ metolachlor, em semeadura convencional. In: CONGRESSO BRASILEIRO DA CIÊNCIA DAS PLANTAS DANINHAS. 20., Caxambu, MG, 1997. Resumos... Viçosa: SBCPD, 1997. p.198.

BLANCO, H. G.; OLIVEIRA, D. de A.; ARAÚJO, J. B. M. Épocas em que uma associação de mato provoca prejuízos por competição ao milho. In: CONGRESSO BRASILEIRO DE 
HERBICIDAS E ERVAS DANINHAS, 11., 1976, Londrina. Resumos... Rolândia: Rolgarf, 1976, p. 18.

CARVALHO, F. T.; GALBIATTI JUNIOR, W.; CAVAZZANA, M. A. Eficiência e seletividade de herbicidas pré-emergentes aplicados sobre nove híbridos de milho. In: CONGRESSO BRASILEIRO DA CIÊNCIA DAS PLANTAS DANINHAS. 20., Caxambu, MG, 1997. Resumos... Viçosa: SBCPD, 1997. p. 204.

DARIO, G. J. A.; DARIO, P. W.; BALTIERI, E. M. Avaliação da eficiência de herbicidas no controle das plantas daninhas ocorrentes na cultura do milho. In: CONGRESSO BRASILEIRO DE HERBICIDAS E PLANTAS DANINHAS, 18., 1993, Londrina. Resumos... Londrina: SBHED, 1993, p. 199-200.

EUROPEAN WEED RESEARCH COUNCIL-EWRC. Methods in weed research. Weed Research, Oxford, v. 4, p. 88, 1964.

LACA-BUENDÍA, J. P.; LEITES, A. Avaliação e seletividade do herbicida Trifluralin (Premerlin), aplicado em pré-emergência no controle de plantas daninhas em milho (Zea mays), em áreas de cerrado. In: CONGRESSO BRASILEIRO DE HERBICIDAS E PLANTAS DANINHAS, 19., 1993, Londrina. Resumos... Londrina: SBHED, 1993, p. 133-134.

LACA-BUENDÍA, J. P.; FERREIRA, J. C. Avaliação da eficácia biológica do herbicida dimethenamid e misturas no controle de plantas daninhas em aplicação na pré-emergência na cultura do milho, em área de cerrado. In: CONGRESSO BRASILEIRO DA CIENCIA DAS PLANTAS DANINHAS, 20., Florianópolis, 1995. Resumos... Florianópolis: SBCPD, 1995. p.122-123.

LACA-BUENDÍA, J. P.; FERREIRA, J. C. Eficácia biológica da atrazine GrDA e SC e do terbuthylate SC no controle pré-emergente de plantas daninhas na cultura do milho (Zea mays L.) In: CONGRESSO BRASILEIRO DA CIÊNCIA DAS PLANTAS DANINHAS, 20., Florianópolis, 1995. Resumos... Florianópolis: SBCPD, 1995. p.124-125.

LACA-BUENDÍA, J. P.; FERREIRA, J.C. Eficácia biológica e seletividade de terbutylazine + metolachlor - MF, no controle de plantas daninhas, através da aplicação na préemergência na cultura do milho (Zea mays L.). In: CONGRESSO BRASILEIRO DA CIÊNCIA DAS PLANTAS DANINHAS. 20., Caxambu, MG, 1997. Resumos... Viçosa: SBCPD, 1997. p. 216.

LEVANTAMENTO SISTEMÁTICO DA PRODUÇÃO AGRÍCOLA. IBGE. Rio de Janeiro, v. 12, n. 3. 72 p. Mar. 1999.

MARCONDES, D. S.; CHEATA, A. N.; FORNAROLI, D. A. Efeitos da adição de óleo vegetal ou espalhante à calda do atrazine na cultura do milho (Zea mays L.). In: CONGRESSO BRASILEIRO DA CIÊNCIA DAS PLANTAS DANINHAS, 2 0., 1997, Caxambu, MG. Resumos... Viçosa: SBCPD, 1997, p. 217.

MASCARENHA, M. H. T.; LARA, J. F. R. Efeito de dosagens e épocas de aplicação da mistura formulada pendimenthalin+atrazine no controle de plantas daninhas na cultura do milho (Zea mays). In: CONGRESSO BRASILEIRO DE HERBICIDAS E PLANTAS DANINHAS, 19., 1993, Londrina. Resumos... Londrina: SBHED, 1993, p. 136-137.

OLIVEIRA, M. L.; OSIPE, R.; SARABIA, J. M. Eficiência no controle de plantas daninhas e seletividade de herbicidas aplicados em pré-emergência, na cultura do milho. In: CONGRESSO BRASILEIRO DE HERBICIDAS E PLANTAS DANINHAS, 18., 1991, Brasília. Resumos... Brasília: SBHPD, 1991, p. 81-82.

RAMOS, L. R. M.; PITELLI, R. A. Efeitos de período de convivência da comunidade infestante sobre a cultura do milho (Zea mays L.) 1- Efeito sobre o rendimento do período crítico de competição. In: CONGRESSO BRASILEIRO DE HERBICIDAS E PLANTAS DANINHAS, 19., 1993, Londrina. Resumos... Londrina: SBHED, 1993, p. 35-36. 
REZENDE, A. M.; LACA-BUENDIA, J. P.; LARA, J. F. R.; TIBÚRCIO, P. C. Eficiência e seletividade da formulação atrazine+butilate para o controle das plantas daninhas na cultura do milho. In: CONGRESSO BRASILEIRO DE HERBICIDAS E PLANTAS DANINHAS, 19., 1993, Londrina. Resumos... Londrina: SBHED, 1993, p. 200-201.

SILVA, J. B. da. Manejo de plantas daninhas na cultura do milho (I). Cultivar, n. 5. p. 37-40. Jun. 1999.

SOUZA, J. R. P. Efeitos de período de controle das plantas daninhas sobre o crescimento e produtividade de quatro híbridos de milho (Zea mays L.). Botucatu. Faculdade de Ciências Agronômicas- UNESP, 1996 (Tese de Doutorado)

VELINI, E. D., FREDERICO, L. A.; BICUDO, S. J.; ANTUNIASSI, U. R. Eficiência de herbicidas pré e pós-emergentes iniciais recomendados para a cultura do milho no controle de plantas daninhas e avaliação de efeitos dos mesmos sobre a produtividade da cultura. In: CONGRESSO BRASILEIRO DE HERBICIDAS E PLANTAS DANINHAS, 19., 1993, Londrina. Resumos... Londrina: SBHED, 1993. p. 141-142. 
Tabela 3- Resultados médios obtidos na avaliação de seletividade e eficácia das formulações com os herbicidas atrazine/ dimethenamidp e atrazine/dimethenamid no controle de plantas daninhas na cultura do milho. Uberaba, MG 1998/99.

\begin{tabular}{|c|c|c|c|c|c|c|c|c|c|c|}
\hline Tratamentos & $\begin{array}{l}\text { Doses } \\
(g / h a)\end{array}$ & $\begin{array}{c}\text { População } \\
\text { Final }\end{array}$ & $\begin{array}{c}\text { Produção } \\
\text { (kg/ha) }\end{array}$ & $\begin{array}{c}\text { Altura } \\
\text { da Planta } \\
(\mathrm{cm})\end{array}$ & $\begin{array}{c}\text { Inserção } \\
1^{\text {a }} \text { Espiga } \\
\text { (cm) }\end{array}$ & $\begin{array}{l}\text { Número } \\
\text { Espiga/ } \\
\text { Parcela }\end{array}$ & $\begin{array}{c}\text { Peso de } \\
100 \\
\text { Sementes } \\
\text { (g) }\end{array}$ & $\begin{array}{c}\text { Colheita } \\
\text { Mecânica } \\
(1-5)\end{array}$ & \multicolumn{2}{|c|}{$\begin{array}{l}\text { Fitotoxicidade } \\
\text { (EWRC } 1 \text { a 9) } \\
7 \text { DAA } 15 \text { DAA }\end{array}$} \\
\hline atrazine+dimethenamid-p & 1800 & $34,0 a^{a(1)}$ & $3399 a$ & $161,4 a b$ & $52,1 \mathrm{ab}$ & $32,8 a b$ & $16,5 a$ & $3,2 d$ & 1,0 & 1,0 \\
\hline atrazine+dimethenamid-p & 2100 & $34,5 a$ & $3508 a$ & $165,5 a$ & $52,9 a b$ & $34,0 a b$ & $17,0 a$ & $3,5 \mathrm{~cd}$ & 1,0 & 1,0 \\
\hline atrazine+dimethenamid-p & 2400 & $33,7 a$ & $3224 a$ & $162,6 a b$ & $52,9 a b$ & $36,8 a$ & $15,6 a$ & $3,8 \mathrm{bcd}$ & 1,0 & 1,0 \\
\hline atrazine+dimethenamid-p & 2700 & $32,0 a$ & $3279 a$ & $163,6 a$ & $51,5 a b$ & $34,0 a b$ & $15,9 a$ & $4,5 \mathrm{ab}$ & 1,0 & 1,0 \\
\hline atrazine+dimethenamid & 2100 & $30,5 a b$ & $3279 a$ & $166,8 a$ & $54,7 a$ & $35,2 a$ & $15,9 a$ & $3,8 \mathrm{bcd}$ & 1,0 & 1,0 \\
\hline atrazine+dimethenamid & 2400 & $34,2 a$ & $3392 a$ & $164,8 \mathrm{a}$ & $50,9 a b$ & $30,5 a b$ & $16,4 a$ & $3,5 \mathrm{~cd}$ & 1,0 & 1,0 \\
\hline atrazine+dimethenamid & 2700 & $34,0 a$ & $3284 a$ & $166,3 a$ & $52,9 a b$ & $37,2 a$ & $15,9 a$ & $3,8 \mathrm{bcd}$ & 1,0 & 1,0 \\
\hline atrazine+dimethenamid & 3000 & $29,7 a b$ & $3337 a$ & $164,1 \mathrm{a}$ & $51,4 a b$ & $36,5 a$ & $16,2 a$ & $4,2 a b c$ & 1,0 & 1,0 \\
\hline s-metolachlor & 2880 & $28,0 a b$ & $3337 a$ & $158,2 a b$ & $49,2 a b$ & $35,5 a$ & $16,2 a$ & $3,2 d$ & 1,0 & 1,0 \\
\hline Testemunha capinada & --- & $33,7 a$ & $3548 a$ & $166,9 a$ & $51,2 a b$ & $34,2 a b$ & $17,3 a$ & $5,0 a$ & 1,0 & 1,0 \\
\hline Testemunha sem capina & --- & $23,0 b$ & $2062 b$ & $148,2 b$ & $46,5 b$ & $18,2 c$ & $11,6 b$ & $1,0 \mathrm{e}$ & 1,0 & 1,0 \\
\hline Média Geral & & 31,6 & 2687 & 162,6 & 51,5 & 32,4 & 15,9 & 3,6 & 1,0 & 1,0 \\
\hline Valor de F & & $4,5^{\star}$ & $10,4^{\star *}$ & $3,3^{* *}$ & $3,7^{*}$ & $12,4^{* *}$ & 7,0 ** & $25,8^{\star \star}$ & & \\
\hline DMS & & 8,3 & 510 & 14,6 & 8,2 & 4,6 & 2,8 & 0,9 & & \\
\hline C. V. (\%) & & 10,7 & 6,4 & 3,6 & 6,4 & 9,9 & 7,1 & 11,2 & & \\
\hline
\end{tabular}

(1) As médias na mesma coluna seguidas pela mesma letra, não diferem estatisticamente entre si, pelo teste de Tukey ao nível de $5 \%$ de probabilidade. DAA $=$ dias após a aplicaç 